\title{
Agricultural Land-Use Changes and Soil Quality: Evaluating Long-Term Trends in a Rural Mediterranean Region
}

\author{
Luca Salvati \\ Consiglio per la Ricerca e la Sperimentazione in Agricoltura, Centro per lo Studio delle Relazioni Pianta-Suolo, \\ Via della Navicella 2-4, 00184 Rome, Italy \\ Correspondence should be addressed to Luca Salvati; bayes00@yahoo.it
}

Received 4 October 2013; Accepted 10 November 2013

Academic Editors: B. J. Allred and A. E. . M. Chirnside

Copyright (C) 2013 Luca Salvati. This is an open access article distributed under the Creative Commons Attribution License, which permits unrestricted use, distribution, and reproduction in any medium, provided the original work is properly cited.

Land-Use Changes (LUCs) are the result of interacting environmental and socioeconomic factors. Although in southern Europe traditional agroforestry systems are an important component of the Mediterranean landscape, intensification and simplification of the rural space coupled with the increasing sensitivity to soil degradation are potentially harmful for the integrity of natural resources and biodiversity stock. The present study introduced a quantitative assessment of rural LUCs that occurred in a region devoted to agriculture and experiencing a progressively higher human impact from both urbanization and land abandonment. The assessment was carried out at the municipality scale along forty years (1970-2010) using data collected every ten years in the framework of the National Census of Agriculture. The Maximum potential Water Capacity (MWC) in the soil, taken as a proxy for agricultural soil quality, and an index of crop intensity have been introduced in the analysis as supplementary variables. A Multiway Factor Analysis (MFA) was developed to evaluate stability or dynamics in the investigated land-use classes. Results illustrate relevant changes in the rural landscape by identifying the classes "moving" towards better soils. An integrated evaluation of rural LUCs and soil resources based on long-time inventories available at an adequate spatial scale is a tool informing policies against soil degradation.

\section{Introduction}

Landscapes are characterised by specific structures (i.e., the spatial arrangement of landscape elements), ecological functions (i.e., how ecological processes operate within that structure), and change dynamics (e.g., disturbance and recovery). Landscape patterns result from physical, biological, and cultural processes acting simultaneously over broad regions [1]. Climate, geology, topography, human disturbance, and land use all influence the composition, configuration, and spatial relationships of landscape elements [2]. Understanding and predicting land-use dynamics was a challenging aspect of landscape ecology since more than twenty years [3].

In Mediterranean Europe, agroforestry systems are important components of the landscape. Anthropogenic pressures and climatic changes are regarded as key factors affecting biodiversity and determining the decline of environmental quality and considerable losses in soil resources (see [4] and the references therein). Rural systems have been evolving in apparently opposite directions in the last fifty years with (i) intensification and simplification of the productions coupled with the increase of ecological fragility in lowlands and (ii) economic marginalisation of mountain areas, with forestation and an increase in grassland area $[5,6]$.

Land-Use Changes (LUCs) were usually assessed through the multitemporal analysis of data collected by remote sensing techniques (see [7] and the references therein). However, long-time-series data on rural LUCs can be obtained also from administrative inventories of crop surfaces and other statistical sources dealing with agriculture matters [8]. Monitoring rural LUCs by statistical inventories has the advantages (i) to allow long-time-series comparisons and (ii) to be available at different spatial and administrative scales (i.e., regions, provinces, and municipalities) which are easily interpretable for nontechnical users, like policy makers and other stakeholders interested in the local scale [9]. Moreover, an approach based on multidimensional analyses of landuse data integrated with other information, for example, soil 
attributes, may better explore latent patterns in rural LUCs and produce indirect information on future trends in the complex soil-landscape system through the elaboration of diachronic indicators [4].

The aim of this paper is to introduce a multitemporal exploratory approach for the assessment of long-term rural LUCs compared with structural characteristics of soils possibly defining their quality for cultivation. Multiway Factor Analysis (MFA) was used to analyse land use and soil data based on administrative sources. The investigated area covers Latium, a Mediterranean region experiencing crop intensification, land abandonment, and urbanization.

\section{Methods}

The study area includes the administrative region of Latium, one of the twenty Italian regions, subdivided into five provinces (Viterbo, Rieti, Rome, Latina, and Frosinone) and 378 local municipalities. It covers an area of approximately $17,065 \mathrm{~km}^{2}$ and is characterised by a complex topography which ranges from 0 to nearly $2.200 \mathrm{~m}$ above sea level, with different climatic zones along the elevation gradient. In the last fifty years, the area has been subjected to a number of land cover changes due to urban growth, tourism development, forest fires, and intensification of agriculture in lowland and hilly areas, as well as the abandonment of agricultural terraces inland [4].

The surface area of seven selected crops was provided every ten years at the municipal level by the National Censuses of Agriculture. Land uses included annual crops (wheat, other cereals, arable land, and grassland) and perennial crops (orchards, grapevine, and olive grove), together with the share of the agricultural utilised area (AUA) to the municipality surface. Land-use variables were obtained as the percent share of each land-use area to the AUA in each municipality. Municipality boundaries weakly changed among 1970 and 2010 and four new municipalities were created in the study area. To make the data collected at the municipality level in the different censuses comparable, we assigned to the few municipalities with no data the average value observed in the three neighbouring municipalities. This procedure was implemented through the ArcGIS (ESRI, Redwoods, USA) software using identification and spatial analyst tools.

A Multiway Factor Analysis (MFA) was applied to the percentages of the eight land cover categories measured at the municipal level in 1970, 1982, 1990, 2000, and 2010. MFA is a generalization of the Principal Components Analysis (PCA) whose goal is to analyse sets of variables collected on the same set of observations [10]. The general objectives of the MFA are (i) to compare and analyse the relationship between the different datasets, (ii) to combine them into a common structure called "compromise" which is then analysed via PCA to reveal the common structure between the observations, and finally (iii) to project each of the original datasets into the compromise to analyse communalities and discrepancies. The weights used to compute the compromise are chosen to make it as representative of all the datasets as possible. Therefore, the MFA allows evaluating if the position
TABLE 1: Distribution of crop intensity index in Latium region by year and elevation zone.

\begin{tabular}{|c|c|c|c|c|}
\hline \multirow{2}{*}{ Year } & \multicolumn{3}{|c|}{ Elevation zones } & \multirow{2}{*}{ Latium } \\
\hline & Lowlands & Hilly areas & Mountain zone & \\
\hline 1970 & 0.85 & 0.77 & 0.42 & 0.66 \\
\hline 1982 & 0.89 & 0.78 & 0.41 & 0.67 \\
\hline 1990 & 0.87 & 0.77 & 0.36 & 0.64 \\
\hline 2000 & 0.90 & 0.74 & 0.33 & 0.62 \\
\hline 2010 & 0.91 & 0.73 & 0.31 & 0.61 \\
\hline
\end{tabular}

of the observations (i.e., rural land cover categories) is stable or changing over time, in order to synthesize changes in different land-use categories by projecting them into the same factor plane [11]. The selected factors are those with absolute eigenvalue $>2$.

Two indicators were introduced in the MFA as supplementary variables: (i) an indicator of crop intensity, originally proposed as a proxy of intensification levels in the rural landscape [4] and (ii) the Maximum Water Capacity (MWC) expressing the maximum water content $(\mathrm{mm})$ a soil can store in optimal climatic conditions [4]. Crop intensity was calculated as the percentage share of cultivated area used for intensive crops in total cultivated area. Intensive crops were classified both as annual crops (i.e., potatoes, vegetables, and other garden crops) and perennial crops (i.e., fruits, grapevine, and olive). The index ranges from 0 to 1 ; higher values indicate crop intensity. Surface areas of different crops were provided at the municipal level by the National Census of Agriculture carried out each decade.

The MWC was derived from a national database of soil characteristics (map of the potential water capacity of agricultural soils in Italy) generated by the Ministry of Agriculture and based on nearly 18,000 soil samples and ancillary thematic cartographies obtained from the National Centre of Pedological Cartography (CNCP) of the Italian Agricultural Research Council. Both indicators were derived at the local scale from the original raster maps using the "zonal statistics" procedure implemented by the ArcGIS software, which assigns a weighted average to each indicator in the municipalities considered.

\section{Results}

Trends in the crop intensity index between 1970 and 2010 in Latium are illustrated in Table 1 according to three elevation zones. The index increased from 0.85 to 0.91 along the last forty years in lowlands, being quite stable in hilly areas and decreasing rapidly in mountain areas. As expected, lowlands in Latium featuring not only dispersed urbanization and tourism pressure but also intensive crop management due to the favourable territorial and climatic conditions showed a marked increase of the index over time. On the other hand, mountain areas with traditional farming systems featured by small-sized farms holding pastures, woods, and low-surface perennial crop showed a general decrease in crop intensity mainly caused by depopulation and land abandonment. 


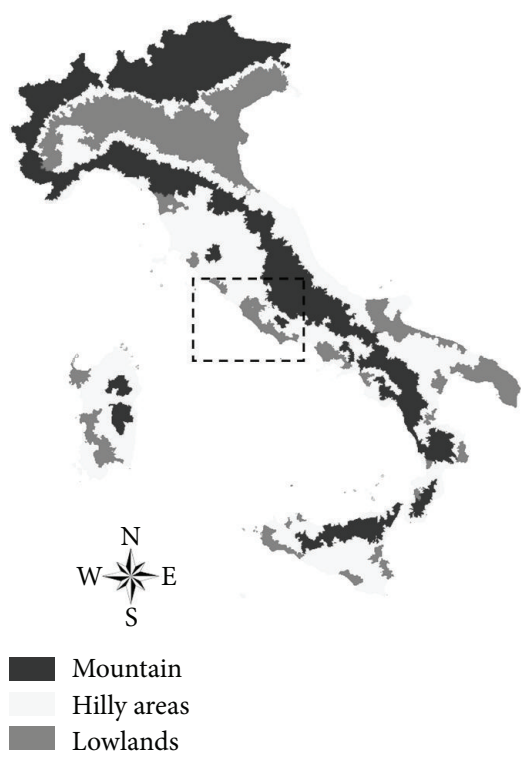

(a)

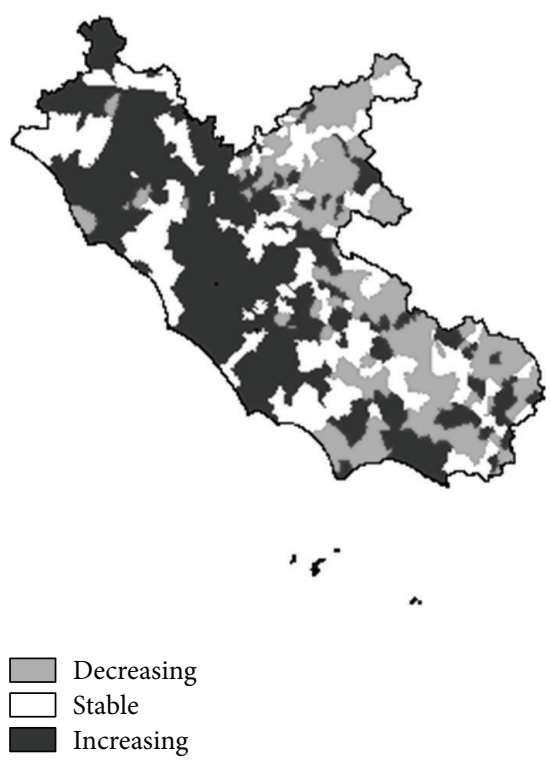

(b)

FIGURE 1: The position of the investigated region in Italy (a) and a map of agricultural intensification (\% change of a crop intensity index) between 1970 and 2010 in Latium (b).

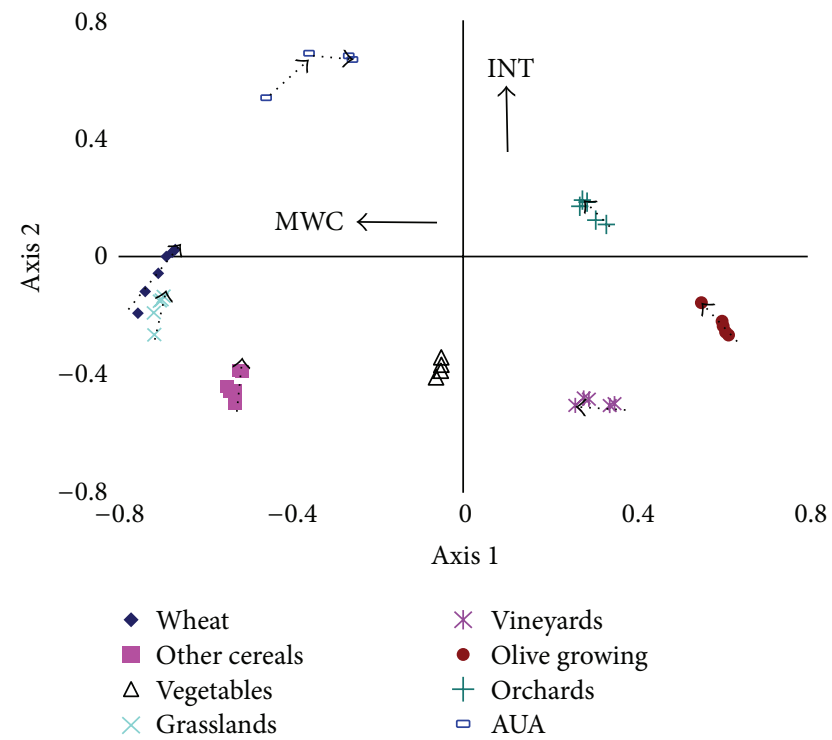

FIGURE 2: MFA results (factor loadings) illustrating rural land-use changes (1970-2010) in Latium, central Italy.

Finally, the changes in the spatial distribution of the index (Figure 1) confirm the existence of a diverging pattern along the elevation gradient.

The MFA applied to the composition of the selected landuse classes observed between 1970 and 2010 extracted two main axes following the criteria mentioned in the methodological chapter and accounting for $25 \%$ and $14 \%$ of the total variance. The MWC correlated negatively with axis 1 while the index of crop intensity was found positively associated to axis 2 (Figure 2). The analysis separates the trajectory of annual crops from that found for perennial crops. MFA results highlight a number of land-use changes that occurred during the investigated period; arrow's length indicates the rapidity in the change of each land use considered. The AUA, being characterized by a slow decline over time, was negatively associated with axis 2 but moving towards its positive values. Wheat moved along the first axis towards the positive values. This indicates a decrease in class area and a slow relocation from lowlands to hilly areas. Similar changes were observed for grassland and olive groves, which are consistent with the trajectory of the AUA.

Taken together, results indicate how municipalities with a higher share of cultivated area are associated, on average, with soils with higher MWC. However, due to the recent changes in rural land uses, cultivated land is progressively moving towards soils with lower MWC, as shown by the MFA. To the contrary, despite declining in the cultivated area, most of the investigated crops moved towards the "intensification axis" (factor 2). This suggests that land abandonment is mainly associated with extensive agricultural systems while all crops stabilize or even increase in areas with economically viable agriculture and intensively farming land.

\section{Discussion}

The present study proposes an integrated evaluation of rural LUCs and defined soil properties based on a multivariate approach based on long-time-series data [4]. Results indicate how the decrease in the area devoted to traditional crops (such as cereals and olive groves) and the spreading of highintensity crops reduce the quality of rural landscapes especially in areas featuring a "historical" attitude to agriculture (e.g., the "Agro Romano" land surrounding the urban municipality of Rome which was cultivated since the Roman age). 
Moreover, this trend can negatively affect rural land biodiversity and poses a question on the long-term sustainability of the agricultural system in Latium.

Rural LUCs, especially those resulting in the intensification of the agricultural system, have environmental consequences [12] which need to be controlled to ensure the sustainability of crop production in agroforestry systems (e.g., [13]). In fact, intensively cultivated landscapes generally prove to be sensitive to soil degradation and poor in biological diversity [14]. This is not only due to conditions of isolation and fragmentation but also to the human pressure at large (e.g., increasing urbanization, soil and water pollution, soil compaction, and soil salinization).

The analysis illustrated here, based on national agricultural inventories, is aimed at summarizing trends and extracting latent patterns of rural LUCs in connection with selected soil attributes (e.g., [8]). The analysis developed may provide detailed spatial information at both regional and local scale by discriminating rapid and slow landscape transformations and identifying specific trajectories of landuse changes [15], thus providing indirect information on their environmental implications. The MFA outputs reflect the main trends in land cover changes anticipated at a very large scale [7] and have the advantage to be easily computable from statistical data sources freely available and frequently updated.

\section{Conclusions}

The increasing demand of quantitative approaches, highresolution data, and indicators suitable to inform environmental policies [9] especially at the local scale should encourage further developments in composite indexes illustrating rural land-use changes [1]. Using soil variables as ancillary variables, these approaches may clarify the implications of land-use changes on the complex interactions among soil and vegetation [6]. Giving spatial information on trends in rural LUCs and, indirectly, on soil quality may represent a tool to the strategies for landscape and soil conservation.

\section{Conflict of Interests}

The author declares no conflict of interests.

\section{References}

[1] J. B. Thornes and J. Brandt, Mediterranean Desertification and Land Use, John Wiley \& Sons, Chichester, UK, 1995.

[2] M. B. Usher, "Statistical models of succession," in Plant Succession: Theory and Prediction, D. C. Glenn-Lewin, R. K. Peet, and T. T. Veblen, Eds., pp. 215-248, Chapman \& Hall, London, UK, 1992.

[3] M. G. Turner, "Landscape ecology: the effect of pattern on process," Annual Review of Ecology and Systematics, vol. 20, pp. 171-197, 1989.

[4] L. Salvati, F. Macculi, S. Toscano, and M. Zitti, "Comparing indicators of intensive agriculture from different statistical source," Biota, vol. 8, no. 1-2, pp. 51-60, 2007.
[5] European Environment Agency, "Towards agro-environmental indicators. Integrating statistical and administrative data with land cover information," Topic Report 6, European Environment Agency, Copenhagen, Denmark, 2001.

[6] OECD, Environmental Indicators for Agriculture. Method and Results. Executive Summary, OECD, Paris, France, 2001.

[7] J. Bouma, G. Varallyay, and N. H. Batjes, "Principal land use changes anticipated in Europe," Agriculture, Ecosystems and Environment, vol. 67, no. 2-3, pp. 103-119, 1998.

[8] J. T. Kerr and J. Cihlar, "Land use and cover with intensity of agriculture for Canada from satellite and census data," Global Ecology and Biogeography, vol. 12, no. 2, pp. 161-172, 2003.

[9] J. Dumanski, W. W. Pettapiece, and R. J. McGregor, "Relevance of scale dependent approaches for integrating biophysical and socio-economic information and development of agroecological indicators," Nutrient Cycling in Agroecosystems, vol. 50, no. 1-3, pp. 13-22, 1998.

[10] C. Lavit, Y. Escoufier, R. Sabatier, and P. Traissac, “The ACT (STATIS method)," Computational Statistics and Data Analysis, vol. 18, no. 1, pp. 97-119, 1994.

[11] R. Coppi and S. Bolasco, Multiway Data Analysis, NorthHolland, Amsterdam, The Netherlands, 1989.

[12] F. B. Brouwer, A. J. Thomas, and M. J. Chadwick, Eds., Land Use Changes in Europe. Processes of Change, Environmental Transformations and Future Patterns, Kluwer Academic, Dordrecht, The Netherlands, 1991.

[13] A. Trisorio, Measuring Sustainability. Indicators For Italian Agriculture, National Institute of Agricultural Economics, Rome, Italy, 2005.

[14] M. R. Moss, "Interdisciplinarity, landscape ecology and the 'Transformation of Agricultural Landscapes"', Landscape Ecology, vol. 15, no. 3, pp. 303-311, 2000.

[15] J. L. Rubio and E. Bochet, "Desertification indicators as diagnosis criteria for desertification risk assessment in Europe," Journal of Arid Environments, vol. 39, no. 2, pp. 113-120, 1998. 

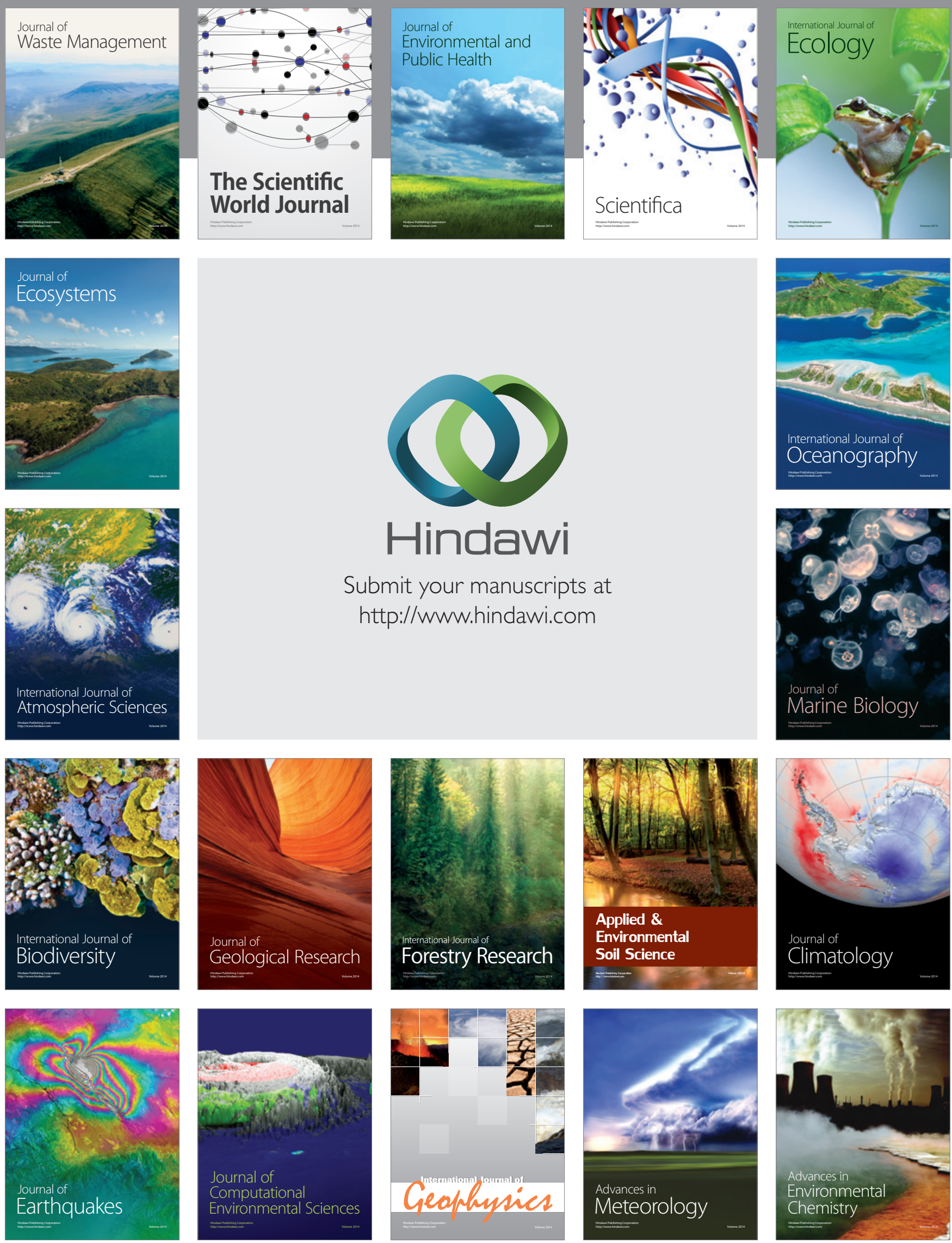